\title{
Coautoría colectiva: analizando una práctica áulica en el espacio universitario
}

\section{Collective co-authorship: analysis of a classroom practice in the university environment}

\author{
Diego Alberto Boyezuk | María Gabriela Muro María Soledad Trigo \\ https://orcid.org/0000-0002-4548-3670 https://orcid.org/0000-0002-1418-490x \\ diegoboyezuk@gmail.com 1 muromaga@hotmail.com Imariasoledadtrigo@hotmail.com
}

$$
\begin{array}{l|l}
\begin{array}{l}
\text { Rubén Omar Arias } \\
\text { https://orcid.org/0000-0002-4932-6891 } \\
\text { iaroa@yahoo.com.ar }
\end{array} & \begin{array}{l}
\text { Carlos Ángel Cordiviola } \\
\text { https://orcid.org/0000-0002-6124-1807 } \\
\text { cordiviolac@gmail.com }
\end{array}
\end{array}
$$

Facultad de Ciencias Agrarias y Forestales | Universidad Nacional de La Plata | Argentina

\section{RESUMEN}

El presente ensayo da cuenta del análisis de una práctica de enseñanza en el ámbito universitario que consistió en la construcción colectiva de la Guía de Estudio del Módulo de Reproducción Animal en coautoría entre los estudiantes de segundo año de la carrera de Ingeniería Agronómica y el equipo docente del Curso de Introducción a la Producción Animal de la Facultad de Ciencias Agrarias y Forestales de la Universidad Nacional de La Plata. Metodológicamente se fundó en el trabajo grupal y en el uso de las nuevas tecnologías informáticas de comunicación como promotores de búsqueda de información en las redes y espacios virtuales académicos. La sistematización y análisis de toda la producción escrita por los estudiantes como la edición final estuvo a cargo del equipo docente. Se concluye que el análisis de nuestras prácticas de enseñanzas en el ámbito áulico nos propone desde un enfoque crítico y reflexivo la indagación como herramienta para la formación profesional continua del ser docente.

\section{ABSTRACT}

This essay gives an account of the analysis of a teaching practice in the university environment that consisted in the collective development of the Study Guide of the Animal Reproduction Module by second year students of the Agricultural Engineering degree course in co-authorship with the teaching team of the Introduction to Animal Production Course of the Faculty of Agricultural and Forestry Sciences of the National University of La Plata. Methodologically, it was based on group work and the use of new communication technologies as promoters of information search in virtual academic networks and spaces. The systematization and analysis of all the production written by the students as the final edition was carried out by the teaching team. It is concluded that the analysis of our teaching practices in the classroom proposes us inquiry from a critical and reflexive approach as a tool for the continuous professional training of the teacher.

PALABRAS CLAVE prácticas de enseñanza, NTICs, sistematización

KEY WORDS

teaching practice, NTICs, systematization 
No sé quién lo dijo, quién acuño semejante reflexión, tal vez sea una frase hecha o una verdad revelada, $u$ otro de los tantos mitos o creencias urbanas, pero lo cierto es que circula frecuentemente y en diferentes espacios la idea que "hoy el conocimiento se encuentra en la palma de las manos"... No es que estemos frente a la retracción física del conocimiento, muy por el contrario, éste se incrementa y expande exponencialmente cada segundo, sino que esta frase hace referencia directa a la facilidad con la que hoy, "celu" por medio, todos o casi todos pueden acceder a toda o casi toda la información. Desde hace aproximadamente cincuenta años, en diferentes oleadas y desde diversas ideologías, se ha anunciado el advenimiento de la sociedad del conocimiento o de la información: un conjunto de transformaciones que cambiarían la base material de nuestro tiempo y espacio. En este sentido, tal vez uno de los fenómenos más espectaculares asociados a este conjunto de transformaciones haya sido la irrupción vertiginosa y globalizante (hasta ahí nomás) de las nuevas tecnologías de la información y la comunicación (NTIC) en todos los ámbitos de nuestras vidas, que de algún modo están cambiando la manera de hacer las cosas: de trabajar, de divertirnos, de relacionarnos y de aprender de modo sutil también están cambiando nuestra forma de pensar (Adell, 1997). La evolución tecnológica permanente a la que hemos asistido en estas últimas décadas ha tenido importantes repercusiones en el ámbito de la educación superior (Gisbert y Esteve, 2011). No obstante, no han sido simétricas y para Darío Sztajnszrajber ${ }^{1}$, en relación al uso y apropiación de las NTIC, existen estudiantes del siglo XXI para docentes del siglo XX en instituciones del siglo XIX. Esta afirmación tiene su correlato en las definiciones de Prensky (2001) quién sostiene que los estudiantes en este nuevo milenio han cambiado, no sólo en su apariencia variando su forma de hablar o de vestir, como ha ocurrido entre generaciones anteriores, sino que esa singularidad se debe al profundo impacto que ha generado la introducción de la tecnología digital en su vida cotidiana.

${ }^{1}$ Conferencia Magistral “El aula ha muerto: reflexiones filosóficas sobre la experiencia postaulica” Dr. Darío Sztajnszrajber en el 3er Congreso Internacional: "Formación de Profesionales de la Educación: Perspectivas y Desafíos Emergentes"Universidad Autónoma Benito Juárez, Oaxaca, México. 25, 26 y 27 de octubre de 2017. 
los estudiantes en este nuevo milenio han cambiado, no sólo en su apariencia variando su forma de hablar o de vestir, como ha ocurrido entre generaciones anteriores, sino que esa singularidad se debe al profundo impacto que ha generado la introducción de la tecnología digital en su vida cotidiana.

Él los llama Nativos Digitales y representan la primera generación que nació, creció y se desarrolla con esta tecnología y como resultado de ello no piensan ni procesan la información de la misma manera que sus predecesores, ya que sus patrones de pensamiento son diferentes, en pocas palabras, estos estudiantes no se corresponden ya con aquellos para cuya enseñanza fueron creados los sistemas educativos tradicionales (Pedró, 2006). El resto de los mortales, y aquí nos encontramos muchos docentes de todos los niveles educativos, somos definidos como Inmigrantes Digitales, personas que, aunque podamos llegar a adaptarnos y aprender a usar cada una de las tecnologías disponibles, no dejamos de perder nuestro acento y de ser extranjeros en un mundo digital. Para los inmigrantes más que un mundo es una selva digital que se nos plantea como algo desconocido, una novedad y como a todo lo desconocido se le teme y todo lo nuevo nos genera incertidumbre, se altera nuestra zona de confort y se ponen en peligro intereses creados (Adell, 1997). Nativos e inmigrantes...he aquí probablemente el primer desencuentro en lo que Achilli (2000) denomina práctica pedagógica, "dialectos" diferentes en procura de un conocimiento, en un espacio común como el aula. Pero hay más. Tanto Nativos como Inmigrantes Digitales nos vemos inmersos en un contexto institucional universitario vetusto. Esta estructura profundamente tradicional, catedrática en muchos casos, cuya organización encorsetada ha caracterizado su enseñanza desde el enciclopedismo del medioevo hasta nuestros días (Menin, 2011) es sostenida por un clásico modelo lineal-disciplinar del currículo en el que se organiza, se ejercita, se crea y se transforma el pensamiento, la percepción de la realidad y la acción humana. Este conocimiento académico aparentemente desideologizado y descontextualizado provoca que el fin originario de la educación como conocimiento social, comprensión del mundo y capacidad para vivir activamente en él quede desdibujado (Torres Santomé, 1998). En esto, poco de azar se percibe y en el actual contexto de capitalismo salvaje que parece no tener fin Martínez Bonafé (2011) nos dice duramente que bajo el paraguas discursivo de "la crisis", se acentúa y desenmascara, más todavía, la voracidad sin límites de unos pocos y el empobrecimiento económico y la idiotización cultural de muchos. Así, más allá de los maquillajes que periódicamente intentan revestir las fachadas de las instituciones educativas particularmente universitarias, el paradigma tecnocrático y el discurso profesionalista se mantiene latente poniendo en tensión permanente las prácticas pedagógicas con fines eman- 
cipadores. Por lo tanto esta dinámica trama cada vez más compleja, conformada por estos estudiantes del nuevo milenio con sus TIC a cuestas, docentes atónitos, enajenados ante lo novedoso e instituciones burocratizadas en blanco y negro en un contexto socio-histórico en technicolor, son el escenario de condiciones implícitas y explicitas donde se regula, configura y determina finalmente el devenir de las prácticas docentes (Martínez Bonafé, 1998; Achilli, 2000).

Partiendo de esta idea y con el objetivo de romper un poco, no mucho, con esta lógica es que como docentes propusimos desafiar nuestras prácticas pedagógicas. Todo surge a partir de la necesidad de digitalizar un "viejo" apunte sobre reproducción animal que se había desarrollado para el Curso de Introducción a la Producción Animal de la Facultad de Ciencias Agrarias y Forestales de la Universidad Nacional de La Plata donde nos desarrollamos como docentes desde hace unos cuantos años. Cabía como posibilidad apelar rápidamente al "facilismo pedagógico" dictar las clases magistrales, trasmitiendo el saber erudito del tema y reescribir el apunte con algunas pinceladas de actualidad para depositar la nueva edición en el aula virtual (toda una innovación) y esperar que pocos días antes del examen parcial los estudiantes acudieran desesperados a engullir la sabiduría contenida en sus páginas. Como diría Freire (1974:75) "...contenidos estáticos, cristalizados. Contenidos que a manera de petrificaciones un sujeto deposita en los otros que dejan inmediatamente de pensar, por lo menos en forma correcta..."

Por esto es que se nos ocurrió tentar a la suerte...enfrentarnos tal vez a la imprevisibilidad áulica y quebrar con el funcionamiento y accionar homogéneo. Desestructurar la rutinaria clase unidireccional y bancaria, que como buenos discípulos aprendimos de nuestros docentes referentes pretéritos y que mantiene en una condición de "sujeto" paciente, casi adormecido a los estudiantes, para entonces, ponerlos en movimiento, desempolvando y activando sus habilidades, creando nuevas y óptimas condiciones en el ámbito áulico a partir de algunas consignas que los guiarían en la construcción de un trabajo de autor.

Poner el eje en el otro...La propuesta a los estudiantes fue que se convirtieran en coautores de la nueva edición de la Guía de estudio del Módulo de Reproducción Animal del Curso de Introducción a la Producción Animal. Solicitamos que aquellos que pudieran, trajeran libros y artículos sobre la temática, pero también algún dispositivo electrónico con el cual poder acceder a Internet como notebook, tablet, teléfonos móviles... "Puede fallar", por lo tanto consensuamos que si ésta idea no funcionaba nos comprometíamos a volver a la "normalidad" académica...

El Curso de Introducción a la Producción Animal se encuentra ubicado en el segundo año de la Carrera de Ingeniería Agronómica de la Facultad de Ciencias Agrarias y Forestales de la Universidad Nacional de La Plata. Cuenta con un régimen de cursada anual (120 horas en dos cuatrimestres) y una matrícula de ochenta estudiantes aproximadamente. 
El Curso de Introducción a la Producción Animal se encuentra ubicado en el segundo año de la Carrera de Ingeniería Agronómica de la Facultad de Ciencias Agrarias y Forestales de la Universidad Nacional de La Plata. Cuenta con un régimen de cursada anual (120 horas en dos cuatrimestres) y una matrícula de ochenta estudiantes aproximadamente.

Durante el primer cuatrimestre, son dos las franjas horarias de cursa$\mathrm{da}$, matutina y vespertina con un número de alumnos equilibrado, por lo tanto las clases, muchas de ellas "magistrales", se deben "dictar" dos veces. Otra necesidad o pretexto para intentar alterar lo estancamente tradicional. El curso, para los estudiantes, representa el primer acercamiento al mundo de la producción animal a través del conocimiento de los diversos sistemas dedicados a la crianza de especies animales de interés zootécnico.

El curso, para los estudiantes, representa el primer acercamiento al mundo de la producción animal a través del conocimiento de los diversos sistemas dedicados a la crianza de especies animales de interés zootécnico.

En este sentido se realiza una aproximación básica a la producción bovina tanto de carne como de leche, la cría de ovinos y caprinos, la porcinocultura, la avicultura, la apicultura y la crianza equina como también la producción cunícola. A priori, brinda las bases conceptuales necesarias para abordar los contenidos de las asignaturas que le siguen en los años posteriores.

En este sentido se realiza una aproximación básica a la producción bovina tanto de carne como de leche, la cría de ovinos y caprinos, la porcinocultura, la avicultura, la apicultura y la crianza equina como también la producción cunícola. A priori, brinda las bases conceptuales necesarias para abordar los contenidos de las asignaturas que le siguen en los años posteriores.

El módulo de reproducción animal se encuentra en el primer cuatrimestre y tiene asignadas diez horas totales en la modalidad teórico-práctico, a decir verdad, más teórico que práctico. En cuanto a los contenidos del módulo, estos fueron desagregados arbitrariamente en cinco "núcleos claves" (Achilli, 2000): 1) Regulación neuro-endócrina de la reproducción y ciclo estral; 2) Anatomía y fisiología del aparato reproductor de la hembra; 3) Gestación, parto, postparto y lactancia; 4) Anatomía y fisiología del aparato reproductor del macho; 5) Biotecnologías de la reproducción.

Al iniciar el primer encuentro, durante los primeros quince minutos del encuentro, se puso en común el objetivo general de la práctica: desarrollar colectivamente la nueva guía o apunte de clase del Módulo de Reproducción Animal. 
Al iniciar el primer encuentro, durante los primeros quince minutos del encuentro, se puso en común el objetivo general de la práctica: desarrollar colectivamente la nueva guía o apunte de clase del Módulo de Reproducción Animal.

Seguidamente se acordó la dinámica del primer día de la experiencia. Se conformarían ocho grupos de cuatro a cinco estudiantes. Cada uno de los primeros cuatro núcleos claves del módulo de reproducción animal sería abordada por dos de los grupos de estudiantes buscando re-significarlos y jerarquizarlos como "núcleos problemáticos" (Achilli, 2000). A partir de una guía de consignas preparadas previamente por el equipo docente, cada uno de los grupos generaría un primer producto escrito sobre la temática que en suerte les había tocado, contando para esta tarea con dos horas. Es importante decir que esta guía no tuvo como finalidad estructurar el trabajo, sino dar ciertos lineamientos a la información producida por los distintos grupos con el objeto de poder ordenarla y sistematizarla posteriormente. Sobre el final de la clase, en plenario, cada grupo expresaría cuales fueron las sensaciones ante la propuesta, como también las fortalezas y debilidades que encontraron al momento de desarrollarla.

Si el movimiento se demuestra andando pues andemos....Vale destacar para comenzar que los grupos no solo se conformaron de manera espontánea, por afinidades y relaciones preexistentes, sino que eligieron libremente los recursos, libros, apuntes, internet, pc, teléfonos, tabletas, entre otros, como así también dispusieron abiertamente del espacio en el cual trabajar. Si bien la primo idea era ocupar completamente el espacio áulico, dos fueron los obstáculos que debieron enfrentar. En primera instancia lo edilicio, un gran anfiteatro con hermosos e inmóviles bancos y pupitres de madera lustrada conspiró con la idea de agrupamiento y el segundo escollo que tuvimos que sortear fue la falta de un buen acceso a internet y ¿dónde está la tal globalización? En consecuencia algún grupo decidió continuar en el aula, otros en el gabinete de informática, otros en el parque o la confitería de la facultad. Menuda caminata para el docente en su función de mediador o facilitador de la tarea. Como siempre el tiempo fue imponiendo los límites del desarrollo de la experiencia, estructurando con algunos grados de flexibilidad los diferentes momentos. Mate y termo a cuestas, recorrimos un par de veces los grupos consultando cómo venían generando la actividad, que inquietudes surgían y percibiendo el grado de avance en relación a los tiempo estipulados, recordando reiteradas veces el regreso del grupo al aula pasadas las dos horas. Transcurrido este lapso nos encontramos nuevamente en el espacio áulico para poner en común, durante los últimos minutos de la jorna$\mathrm{da}$, todas y cada una de las sensaciones que la experiencia les produjo. Si bien hubo un poco de catarsis estudiantil, la propuesta didáctica fue aprobada por la mayoría.

Comenzando el segundo encuentro, acordamos que los grupos que tenían en común una temática específica debían juntarse, compartir 
lo realizado hasta entonces, debatir y consensuar un solo producto, elaborando un informe digital, cuyas pautas y formato de escritura fueron consignadas previamente durante estos primeros minutos del encuentro, y una presentación en Power Point para ser expuesta en plenario al día siguiente para el resto de los grupos y el equipo docente del Curso. Nuevamente y con toda la libertad, los grupos se juntaron y dispusieron de todos los recursos y de los espacios, el tiempo, como cuota de poder, lo fui flexiblemente administrando con la finalidad de alcanzar las consignas del día. En el devenir recorrí grupo por grupo una y otra vez, intentando intervenir solo de manera orientativa en la dinámica grupal, proponiendo la crítica y reflexión sobre la acción que estaban llevando adelante. No todos los grupos lograron terminar el informe y el Power Point al finalizar el encuentro. No hubo homogeneidad en este sentido. Cada uno de los grupos tuvo un tiempo, su tiempo para todo.

Dispusimos conjuntamente al iniciar la tercera jornada utilizar los primeros cuarenta y cinco minutos de la clase para terminar la entrega de los informes que pudieran haber quedado pendientes del día anterior y preparar las diferentes presentaciones grupales que serían puestas en plenario. Esta vez sí el espacio áulico del anfiteatro fue el único ámbito de trabajo para todos los grupos y el docente. Realicé una última recorrida por los grupos con el fin de observar cómo se iba cerrando una experiencia innovadora. Al menos para estos estudiantes y para nosotros (Zabalza, 2012). Contando con los recursos audiovisuales necesarios, las presentaciones en Power Point se llevaron adelante siguiendo el orden asignado arbitrariamente al principio de la práctica. Fueron expuestas con solvencia por los estudiantes con mi moderación e intervención puntual en los momentos que surgía alguna inquietud o propiciaba una necesaria aclaración temática. Los informes digitales presentados por los diferentes grupos fueron ordenados, sistematizados y editados por el equipo docente durante el desarrollo del resto de la semana conformando la Guía o Apunte del Módulo de Reproducción Animal.

La frase "una imagen vale más que mil palabras" es una vieja expresión que hace alusión a la fuerza que poseen las imágenes para transmitir, explicar o mostrar determinados aspectos difíciles, en muchas ocasiones, de ser plasmados por escrito. Teniendo en cuenta que nuestros estudiantes, como se dijo son nativos digitales y se han criado en un tiempo en el que lo visual y la imagen dinámica se han consolidado como herramientas comunicacionales casi globales, este último encuentro basó su estrategia didáctica en la proyección de un video que resume los aspectos tratados en cada una de las áreas temáticas y logra integrarlos en la praxis cotidiana de las biotecnologías aplicadas al campo de la reproducción animal como lo son la sincronización de celos, la inseminación artificial, entre otros. Para finalizar se puso en consideración de los presentes toda la práctica pedagógica. Como siempre sucede, no todos estuvieron conformes incluyendo algunos colegas docentes que sintieron su zona de confort en peligro. Hubo estudiantes que pasada la práctica expresaron que hubieran preferido clases "tradicionales", pero en su gran mayoría se sintieron interpelados por una propuesta innovadora. 


\section{ALGUNAS REFLEXIONES FINALES}

Si bien como docente no buscamos con esta experiencia quedar plasmados en la futura memoria emotiva de los estudiantes como ocurrió con la Señora Henzi profesora de álgebra citada por Jackson (1999), sí intentamos, al menos, provocar efectos positivos sobre ellos. Todas las actividades descriptas, estrategias de una configuración didáctica como la realizada conjuntamente con los estudiantes del Curso de Introducción a la Producción Animal en torno a la construcción colectiva de la Guía de estudio del Módulo de Reproducción Animal, se enmarcan sin lugar a duda en lo que Edelstein (2005: 140) denomina prácticas de enseñanza, entendiéndose por tales a las prácticas sociales, históricamente determinadas, que generadas en un tiempo y un espacio concretos propician una actividad intencional que pone en juego un complejo proceso de mediaciones orientado a imprimir explícita o implícitamente algún tipo de racionalidad a las prácticas que tienen lugar particularmente, en el interior del aula. El caso de esta experiencia vivida como práctica social contextualizada, simplemente y a partir de una intencional decisión oportuna en torno a una dimensión central como es el problema del conocimiento, no siguió el mito de la "fabricación" (Merieux, 1998), la tradicional acción prescriptiva de transferencia tecnicista, una configuración no didáctica que tiende a la enajenación docente y pone a los estudiantes en una actitud pasiva, sino que colectivamente intentamos establecer otra relación con el conocimiento, una relación dialógica-comunicativa. "No hay pensamiento aislado, así como no hay hombre aislado" nos decía el pedagogo y en todo acto de conocimiento, hay un sujeto que piensa, un objeto pensado que mediatiza al primer sujeto del segundo a través de la comunicación (Freire, 1974:74). No hay un "pienso" sino un "pensamos" y en este acto, que implica reciprocidad, no hay sujetos pasivos, sino sujetos particulares, en un ámbito particular frente a un objeto de estudio particular Al respecto Edelstein (1996) entiende que esto implica reconocer al docente como sujeto disruptivo en su praxis que, desde su trayectoria de vida y formación, asume la tarea de elaborar una propuesta de enseñanza en la cual lo metodológico como construcción deviene de un acto singularmente creativo de articulación entre la lógica disciplinar, las posibilidades de apropiación de ésta por parte de los sujetos y las situaciones y los contextos particulares que constituyen los ámbitos donde ambas lógicas se entrecruzan. Esta adopción intencional por parte del docente de una perspectiva axiológica, ideológica como visión del mundo incide en la vinculación con el conocimiento. Es aquí donde el análisis de nuestras prácticas de enseñanza en el ámbito áulico nos propone desde un enfoque crítico y reflexivo la indagación como herramienta para la formación profesional continua del ser docente. Al respecto Achilli (2000) nos acerca diferentes modos de vinculación entre la formación, las prácticas docentes y el conocimiento. Nuestra experiencia como práctica pedagógica adscribe al modo relacional de apropiación dialéctica del conocimiento que implica un trabajo reflexivo, de constrastación crítica del conocimiento acumulado a partir de entender o conocer su lógica, sus 
fundamentos y sus diferenciaciones como base que permita realizar selecciones pertinentes, evaluarlo en su interacción con los sujetos de aprendizaje, transformar y transformarse en las prácticas de enseñanza. Este "trabajo intelectual" que sostiene Achilli o "conocimiento de la práctica" o "indagación como actitud" en palabras de Cochran-Smith y Lytle (2003) permite una comprensión más estrecha de las relaciones entre el conocimiento y la práctica, así como sobre el modo en que la indagación produce información. Aquí no se divide el universo del saber en teoría y praxis, sino que se asume que el conocimiento que los docentes necesitan se genera "in situ", cuando ellos mismos reconocen a sus aulas como lugares de investigación explicita, al mismo tiempo que consideran los conocimientos y teorías producidos por otros como insumo que sirve para generar interrogante e interpretaciones. En este sentido los docentes aprendemos cuando construimos conocimiento localizado en la práctica conectándolo con aspectos sociales, culturales y políticos más amplios. Desde esta perspectiva de indagación sobre la práctica como posicionamiento, el desarrollo profesional docente tiene más que ver con la incertidumbre que con la certidumbre, con el planteamiento de problemas que con su resolución y con el reconocimiento de que el espíritu de búsqueda procede de la interpelación y desemboca también en ella.

el desarrollo profesional docente tiene más que ver con la incertidumbre que con la certidumbre, con el planteamiento de problemas que con su resolución y con el reconocimiento de que el espíritu de búsqueda procede de la interpelación y desemboca también en ella. 


\section{BIBLIOGRAFIA}

Adell J. 1997.Tendencias en educación en la sociedad de las tecnologías de la información. Edutec-e Revista electrónica de tecnología educativa $\mathrm{N}^{\circ} 7$.

Cochran-Smith M, Lytle. 2003. Más allá de la certidumbre: adoptar una actitud indagadora sobre la práctica. En: La indagación como base de la formación del profesorado y la mejora de la educación. Coord. Lieberman, A.; Miller, L. págs. $65-80$.

Edelstein G. 1996. Un capítulo pendiente: el método en el debate didáctico contemporáneo. En: Corrientes Didácticas Contemporáneas. Ed. Paidos Cuestiones de Educación.

Edelstein G. 2005. Enseñanza, política de educación y construcción didáctica. Educar ese acto político. Comp. Frigerio, G. yDiker, G. Del Estante Editorial, Buenos Aires.

Freire P. 1973. ¿Extensión o comunicación? La concientización en el medio rural. Siglo XXI editores.

Gisbert M, F Esteve. 2011. Digital Leaners: la competencia digital de los estudiantes universitarios. La cuestión Universitaria. pp 48-59. En línea.

Jackson P. 1992. Los afanes cotidianos. Cap. I en La vida en las aulas. Ed. Morata. Madrid.

Jackson P. 1999. Enseñanzas implícitas. Ed. Amorroutu. Agenda Educativa. Buenos Aires.

Martínez Bonafé J. 1998. Trabajar en la escuela. Profesorado y reformas en el umbral del siglo XXI. Madrid. Miño y Dávila Editores. En línea.

Martínez Bonafé J. 2011. Enseñar en la Universidad Pública. Sujeto, conocimiento y poder en la Educación Superior.Forum Mundial de Educaçao. En: http://almanaquefme.org/?p=1329.

Menin O. 2011. Algunas ideas sobre formación docente universitaria. Praxis Educativa XV(15):14-18. FCH Universidad Nacional de La Pampa. En línea.

Merieu P. 1998.Frankestein educador. Laertes. Barcelona.

Pedró F. 2006.Aprender en el nuevo milenio: Un desafío a nuestra visión de las tecnologías y la enseñanza. OECD - CERI Centre for educational research and innovation. Enlínea.

Prensky M. 2001. Digital natives, digital inmigrant. On the Horizon. MBC University Press. Vol 9:5. En línea. 
Torres Santomé J. 1994. Globalización e interdisciplinariedad: el currículo integrado. Tercera edición. Morata SL. En línea.

Zabalza M, ACerdeiriña. 2012. Innovación y cambio en las instituciones educativas. Ed. Homo Sapilns. 